\title{
ANALISA KESEIMBANGAN LINTASAN PRODUKSI PADA PEMBUATAN RADIATOR MITSUBISHI PS 220 DENGAN METODE RANKED POSITIONAL WEIGHT (RPW)
}

\author{
Henri Ponda ${ }^{\text {1) }}$, Joko Hardono ${ }^{2)}$, Sofi Khaerul Pikri ${ }^{3)}$ \\ ${ }^{1,2,3)}$ Program Studi Teknik Industri, Fakultas Teknik \\ Universitas Muhammadiyah Tangerang \\ Jl. Perintis Kemerdekaan I/33 Cikokol, Kota Tangerang \\ E-mail : jhardono@yahoo.com, henri_ponda@umt.ac.id
}

\begin{abstract}
A b s tract
Increasing demand for Mitsubishi Fuso FN 527220 PS trucks will demand increased production of Mitsubishi PS 220 radiators at PT. Anugerah Aneka Industri. In making tank components through 2 processes, namely the press tank and tank assy. Making core components through 3 processes namely core assy, oven and end plate installing. Making end plate components through 1 process, namely the press end plate. Making side plate components through 4 processes, namely punch, shering, bending and spot. Then the components are assembled through 5 processes, namely tanks installing, installing side plates, leaks, painting, and packaging.
\end{abstract}

The purpose of this research is to get a standard working time and line balancing to provide additional information on the process of making Mitsubishi PS 220 radiator products so that it is easy to determine production work against consumer demand. Standard time is measured using the stop hour method, while line balancing uses the Ranked Positional Weight (RPW) method. Standard time and line balancing data is processed using Microsoft Excel 2016 software.

Finally from the results processing of standard time data and line balancing obtained the number of efficient workstations is 8 workstations, idle time 10.8 minutes, balance free time (balance delay) $12.36 \%$, efficiency of production lines (line efficiency) $87.64 \%$.

Key words : Workstation, Waktu Baku, Jam Henti, Line Balancing, Ranked Positional Weight (RPW).

\section{PENDAHULUAN}

Semakin berkembangnya perindustrian di Indonesia membuat banyaknya permintaan alat transportasi untuk membawa produk ke berbagai kota maupun daerah di Indonesia. Salah satu alat transportasi yang digunakan untuk membawa produk adalah truk Mitsubishi Fuso FN 527220 PS atau disingkat dengan Mitsubishi PS 220 yang dilengkapi dengan radiator untuk pendinginan mesin. Banyaknya permintaan akan truk Mitsubishi Fuso FN 527220 PS menyebabkan meningkatnya permintaan akan radiator. Perusahaan pembuat radiator di tuntut dalam meningkatkan sumber daya yang tersedia seoptimal mungkin untuk menghasilkan tingkat produk semaksimal mungkin dari segi kuantitas tanpa mengurangi kualitas produk sedikitpun.

PT. Anugerah Aneka Industri (PT. AAI) adalah salah satu perusahaan yang bergerak di bidang radiator otomotif dan non otomotif. Salah satu produk yang ditawarkan adalah radiator truk tipe Mitsubishi PS 220. Radiator truk tipe Mitsubishi PS 120 terdiri dari komponen tank, core, end plate dan side plate. Pembuatan komponen tank melalui 2 proses yaitu press tank dan tank assy. Pembuatan komponen core melalui 3 proses yaitu rakit core, oven dan pasang end plate. Pembuatan komponen end plate melalui 1 proses yaitu press end plate. Pembuatan komponen side plate melalui 4 proses yaitu punch, shering, bending dan spot. Lalu komponen-komponen tersebut dirakit melalui 5 proses yaitu pasang tank, pasang side plate, leaktest, painting, dan packaging. 
Namun semakin meningkatnya permintaan akan radiator truk tipe Mitsubishi PS 220 dan tidak adanya informasi waktu baku pembuatan radiator Mitsubishi PS 220, menyebabkan beberapa kendala dalam perencanaan target produksi. Tidak samanya waktu pengerjaan dalam setiap proses menyebabkan tidak seimbangnya proses pembuatan radiator. Berdasarkan pengamatan yang dilakukan, proses produksi yang berlangsung pada pembuatan radiator Mitsubishi PS 220 belum berjalan dengan baik sehinga menyebabkan ketidakseimbangan lintasan.

Ketidakseimbangan lintasan dalam kegiatan produksi dapat dilihat dari menganggurnya beberapa stasiun kerja, sedangkan di stasiun kerja lainnya tetap bekerja secara penuh. Hal ini disebabkan oleh waktu yang dibutuhkan oleh suatu stasiun kerja untuk menyelsaikan pekerjaan lebih dari kecepatan lintasan yang telah ditentukan. Kecepatan lintasan tersebut ditentukan dari tinkat kapasitas, permintaan, serta waktu operasi terpanjang (Kusuma, 2007).

Oleh karena itu, proses penyeimbangan lintasan (line balancing) perlu dilakukan untuk menciptakan keseimbangan dari jalur produksi sehingga proses produksi akan berjalan lancar. Penyeimbangan lintasan (line balancing) merupakan konsep memilah atau mengelompokkan tugas produksi ke dalam beberapa stasiun kerja, agar tercipta suatu arus produksi yang mulus. Dan perbedaan skill operator pun menjadi salah satu faktor dalam kecepatan maupun hasil dari suatu produk dan tidak adanya peta proses operasi membuat kurangnya informasi dalam proses produksi sehingga terjadinya miskomunikasi.

Perusahaan dituntut agar bisa memberikan informasi yang lebih cepat dalam menangani permintaan konsumen. Hal ini agar lebih mudah dalam memberikan informasi kepada kosumen serta memudahkan proses perencanaan target produksi. Dengan adanya standar penetapan informasi waktu baku, penyeimbangan lintasan dan peta proses operasi, maka secara teknis dapat membantu mengetahui secara tepat estimasi waktu pembuatan radiator tersebut.

\section{METODE PENELITIAN}

\section{Identifikasi Masalah}

Berdasarkan permasalahan di atas, maka identifikasi masalah penelitian ini dirumuskan sebagai berikut:

1. Tidak adanya standar waktu pengerjaan yang dibakukan dalam proses pembuatan radiator pada setiap workstation.

2. Terjadinya ketidakseimbangan dalam proses pembuatan radiator yang menyebabkan waktu pengerjaan lebih lama dari elemen kerja lainnya.

3. Tidak efisiensinya lintasan pada proses pembuatan radiator Mitsubishi PS 220.

\section{Tujuan Penelitian}

Berdasarkan rumusan masalah, maka tujuan yang akan dicapai adalah:

1. Mengetahui waktu baku proses pembuatan radiator Mitsubishi PS 220.

2. Mengetahui workstation mana yang menyebabkan ketidakseimbangan waktu proses pengerjaan lebih lama dari workstation lainnya.

3. Mengetahui lintasan yang efisien pada proses pembuatan radiator Mitsubishi PS 220 .

\section{Teknik Pengumpulan Data}

Beberapa metode pengumpulan data yang digunakan dalam penelitian ini adalah :

1. Observasi

Metode ini dilakukan dengan cara pengamatan dan pengumpulan data secara langsung di perusahaan yang bersangkutan. Alat yang digunakan untuk pengukuran adalah jam henti (stopwatch).

2. Studi Pustaka

Metode ini dilakukan dengan cara mencari dan mengumpulkan data berdasarkan dari referensi atau literatur yang berhubungan dengan bahasan masalah.

3. Wawancara

JIM, Vol. 4, No. 1, Januari 2019, pp.77- 92 
Dalam metode ini pengumpulan data diperoleh lewat tanya jawab secara langsung kepada pihak perusahaan yang terkait.

\section{Teknik Analisis}

Dalam penyusunan laporan ini digunakan metode pengolahan dan analisa datanya adalah sebagai berikut:

1. Menghitung waktu rata-rata

$$
\bar{x}=\frac{\sum x i}{n}
$$

2. Melakukan uji keseragaman data

$$
\begin{aligned}
& S d=\sqrt{\frac{\sum(x i-\bar{x})^{2}}{n-1}} \\
& \mathrm{BKA}=\bar{x}+3 \mathrm{Sd} \\
& \mathrm{BKB}=\bar{x}-3 \mathrm{Sd}
\end{aligned}
$$

3. Melakukan uji kecukupan data

$$
N^{\prime}=\left[\frac{\frac{k}{s} \sqrt{N \sum x^{2}-\left(\sum x\right)^{2}}}{\sum x}\right]^{2}
$$

4. Menentukan penyesuaian dan kelonggaran

5. Menghitung waktu siklus

$$
W s=\frac{\sum x i}{n}
$$

6. Menghitung waktu normal

$$
W n=W s . p
$$

7. Menghitung waktu baku

$$
W b=(W n \cdot R f) \frac{100}{100-A l l}
$$

8. Membuat peta proses operasi

9. Membuat diagram aliran

10. Membuat Precedence diagram

11. Menentukan waktu stasiun kerja terbesar

12. Menentukan stasiun kerja

$$
K=\frac{\sum t i}{C} x 100 \%
$$

13. Menghitung waktu menganggur (idle time)

$$
\text { Idle Time }=W s-W i
$$

14. Menghitung keseimbangan waktu senggang (balance delay)

$$
B D=\frac{n . C-\sum t i}{n . t i} x 100 \%
$$

15. Menghitung efisiensi lintasan produksi (line efficiency)

$$
\text { Eff }=\frac{s T i}{n . C} \times 100 \%
$$

\section{HASIL DAN PEMBAHASAN}

Pada penelitian di PT. Anugerah Aneka Industri (PT. AAI), penulis melakukan pengumpulan data dengan mengukur waktu proses pembuatan radiator Mitsubishi PS 220. Alat yang digunakan untuk pengukuran adalah jam henti (stopwatch). 
Tabel 1 Waktu Proses Operasi

\begin{tabular}{|c|c|c|c|c|c|c|c|c|}
\hline \multirow{2}{*}{ Sample } & \multicolumn{7}{|c|}{ Waktu (Detik) } \\
\cline { 2 - 9 } & $\begin{array}{c}\text { WS 1 } \\
\text { (Rakit } \\
\text { Core) }\end{array}$ & $\begin{array}{c}\text { WS 2 } \\
\text { (Oven) }\end{array}$ & $\begin{array}{c}\text { WS 3 } \\
\text { (Press } \\
\text { EP) }\end{array}$ & $\begin{array}{c}\text { WS 4 } \\
\text { (Pasang } \\
\text { EP) }\end{array}$ & $\begin{array}{c}\text { WS 5 } \\
\text { (Press } \\
\text { Tank) }\end{array}$ & $\begin{array}{c}\text { WS 6 } \\
\text { (Tank } \\
\text { Assy) }\end{array}$ & $\begin{array}{c}\text { WS 7 } \\
\text { (Pasang } \\
\text { Tank) }\end{array}$ & $\begin{array}{c}\text { WS 8 } \\
\text { (Punch) }\end{array}$ \\
\hline 1 & 451 & 258 & 197 & 196 & 225 & 245 & 244 & 245 \\
\hline 2 & 453 & 255 & 196 & 199 & 223 & 244 & 249 & 242 \\
\hline 3 & 452 & 259 & 195 & 198 & 224 & 242 & 247 & 244 \\
\hline 4 & 455 & 258 & 193 & 197 & 225 & 246 & 244 & 246 \\
\hline 5 & 457 & 255 & 194 & 198 & 222 & 244 & 245 & 242 \\
\hline 6 & 455 & 254 & 196 & 196 & 223 & 242 & 246 & 244 \\
\hline 7 & 453 & 257 & 198 & 200 & 221 & 243 & 248 & 243 \\
\hline 8 & 454 & 260 & 194 & 198 & 224 & 245 & 248 & 245 \\
\hline 9 & 456 & 258 & 197 & 200 & 225 & 247 & 246 & 247 \\
\hline 10 & 453 & 257 & 196 & 199 & 223 & 243 & 247 & 245 \\
\hline 11 & 451 & 256 & 193 & 197 & 223 & 245 & 248 & 243 \\
\hline 12 & 454 & 254 & 194 & 198 & 222 & 242 & 249 & 242 \\
\hline 13 & 452 & 255 & 197 & 196 & 221 & 243 & 246 & 244 \\
\hline 14 & 454 & 256 & 195 & 198 & 225 & 244 & 245 & 243 \\
\hline 15 & 453 & 256 & 194 & 197 & 224 & 243 & 246 & 243 \\
\hline Rata & $\mathbf{4 5 3 , 5}$ & $\mathbf{2 5 6 , 5}$ & $\mathbf{1 9 5 , 3}$ & $\mathbf{1 9 7 , 8}$ & $\mathbf{2 2 3 , 3}$ & $\mathbf{2 4 4 , 1}$ & $\mathbf{2 4 6 , 4}$ & $\mathbf{2 4 4 , 3}$ \\
\hline
\end{tabular}

Tabel 1 Waktu Proses Operasi (lanjutan)

\begin{tabular}{|c|c|c|c|c|c|c|c|}
\hline \multirow[b]{2}{*}{ Sample } & \multicolumn{7}{|c|}{ Waktu (Detik) } \\
\hline & $\begin{array}{c}\text { WS 9 } \\
\text { (Shering) }\end{array}$ & $\begin{array}{c}\text { WS 10 } \\
\text { (Bending) }\end{array}$ & $\begin{array}{c}\text { WS } \\
11 \\
\text { (Spot) }\end{array}$ & $\begin{array}{c}\text { WS } 12 \\
\text { (Pasang } \\
\text { SP) }\end{array}$ & $\begin{array}{c}\text { WS 13 } \\
\text { (Leaktest) }\end{array}$ & $\begin{array}{c}\text { WS } 14 \\
\text { (Painting) }\end{array}$ & $\begin{array}{c}\text { WS } 15 \\
\text { (Packaging) }\end{array}$ \\
\hline 1 & 78 & 88 & 137 & 208 & 176 & 492 & 89 \\
\hline 2 & 77 & 89 & 138 & 209 & 179 & 494 & 90 \\
\hline 3 & 79 & 86 & 139 & 207 & 178 & 496 & 89 \\
\hline 4 & 81 & 87 & 136 & 206 & 177 & 495 & 88 \\
\hline 5 & 80 & 85 & 135 & 207 & 176 & 493 & 90 \\
\hline 6 & 78 & 88 & 137 & 205 & 178 & 495 & 88 \\
\hline 7 & 76 & 86 & 136 & 206 & 180 & 492 & 91 \\
\hline 8 & 77 & 90 & 138 & 209 & 178 & 494 & 89 \\
\hline 9 & 80 & 89 & 137 & 208 & 179 & 496 & 90 \\
\hline 10 & 79 & 87 & 139 & 207 & 180 & 495 & 91 \\
\hline 11 & 76 & 88 & 135 & 205 & 178 & 494 & 88 \\
\hline 12 & 78 & 86 & 135 & 207 & 178 & 491 & 89 \\
\hline 13 & 77 & 87 & 139 & 209 & 176 & 492 & 90 \\
\hline 14 & 80 & 90 & 137 & 205 & 177 & 493 & 90 \\
\hline 15 & 78 & 89 & 135 & 205 & 178 & 491 & 91 \\
\hline Rata & 78,5 & 87,7 & 136,9 & 206,9 & 177,9 & 493,5 & 89,5 \\
\hline
\end{tabular}




\section{Perbandingan Waktu Baku Tiap Workstation}

Tabel 2 Perbandingan Waktu Baku Tiap Workstation

\begin{tabular}{|c|c|c|}
\hline Workstation & $\begin{array}{c}\text { Waktu } \\
\text { (detik) }\end{array}$ & $\begin{array}{c}\text { Waktu } \\
\text { (menit) }\end{array}$ \\
\hline $\mathbf{1}$ & 559,9 & 9,3 \\
\hline $\mathbf{2}$ & 378,7 & 6,3 \\
\hline $\mathbf{3}$ & 264,9 & 4,4 \\
\hline $\mathbf{4}$ & 292,0 & 4,9 \\
\hline $\mathbf{5}$ & 303,0 & 5,0 \\
\hline $\mathbf{6}$ & 358,6 & 6,0 \\
\hline $\mathbf{7}$ & 327,5 & 5,5 \\
\hline $\mathbf{8}$ & 358,6 & 6,0 \\
\hline $\mathbf{9}$ & 113,4 & 1,9 \\
\hline $\mathbf{1 0}$ & 127,1 & 2,1 \\
\hline $\mathbf{1 1}$ & 198,4 & 3,3 \\
\hline $\mathbf{1 2}$ & 274,8 & 4,6 \\
\hline $\mathbf{1 3}$ & 258,5 & 4,3 \\
\hline $\mathbf{1 4}$ & 655,7 & 10,9 \\
\hline $\mathbf{1 5}$ & 126,1 & 2,1 \\
\hline
\end{tabular}

\section{Perbandingan Waktu Baku}

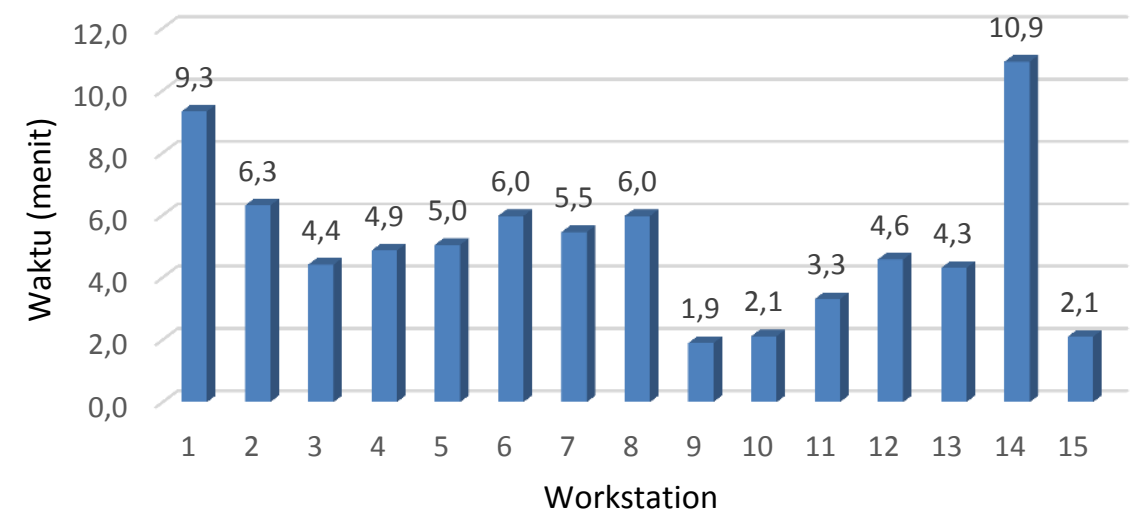

Gambar 1 Diagram Perbandingan Waktu Baku

Berdasarkan gambar 1 diatas menunjukkan bahwa terjadinya ketidakseimbangan lintasan produksi dalam pembuatan radiator PS220. Sehingga terdapat beberapa stasiun kerja yang menganggur dan stasiun kerja yang tidak menganggur. 
Peta Proses Operasi dan Diagram Aliran Proses

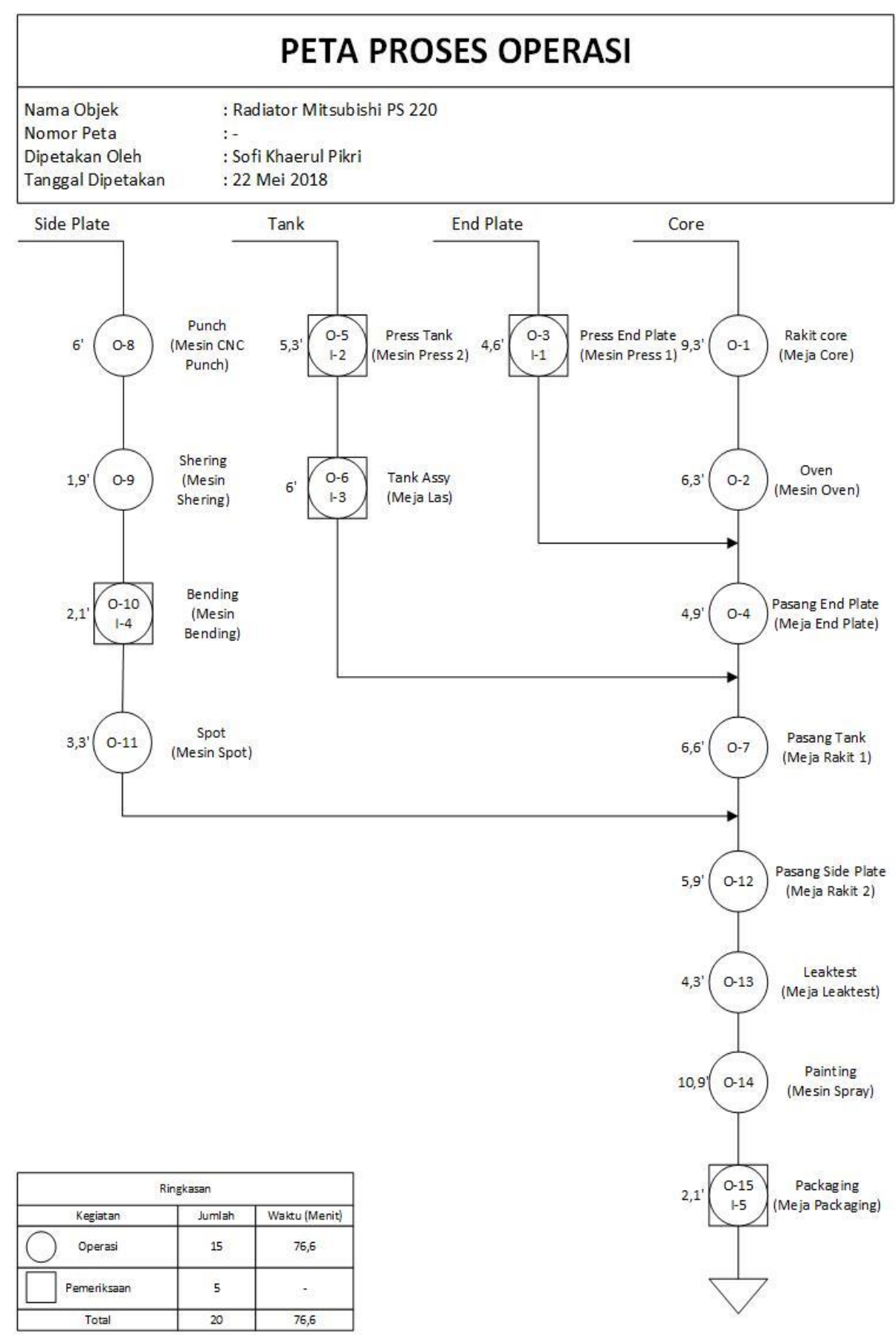

Gambar 2 Peta Proses Operasi Radiator Mitsubishi PS 220. 


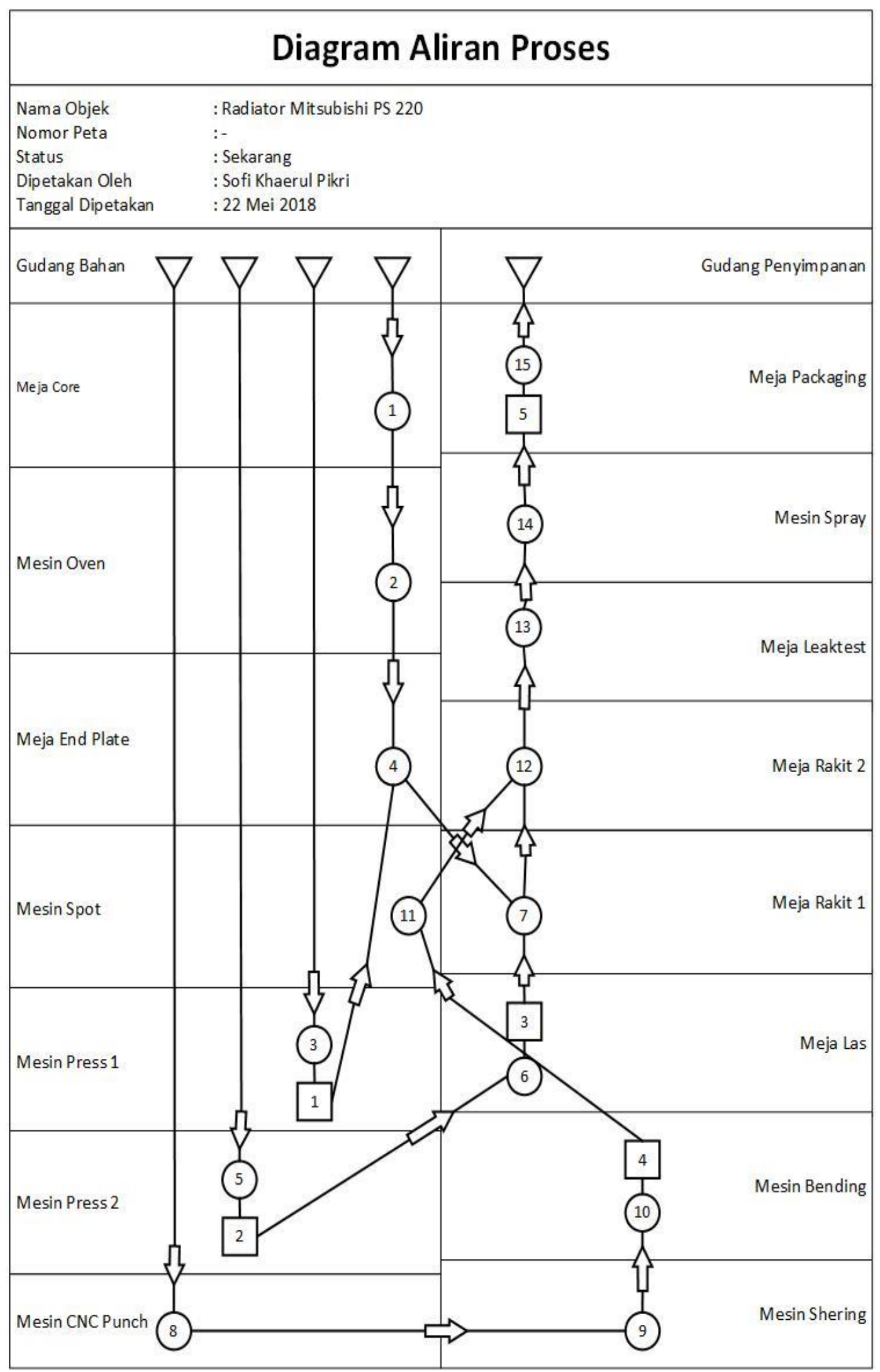

Gambar 3 Diagram Aliran Proses Radiator Mitsubishi PS 220 


\section{Precedence Diagram}

Precedence diagram dibuat berdasarkan peta proses operasi pada gambar 2

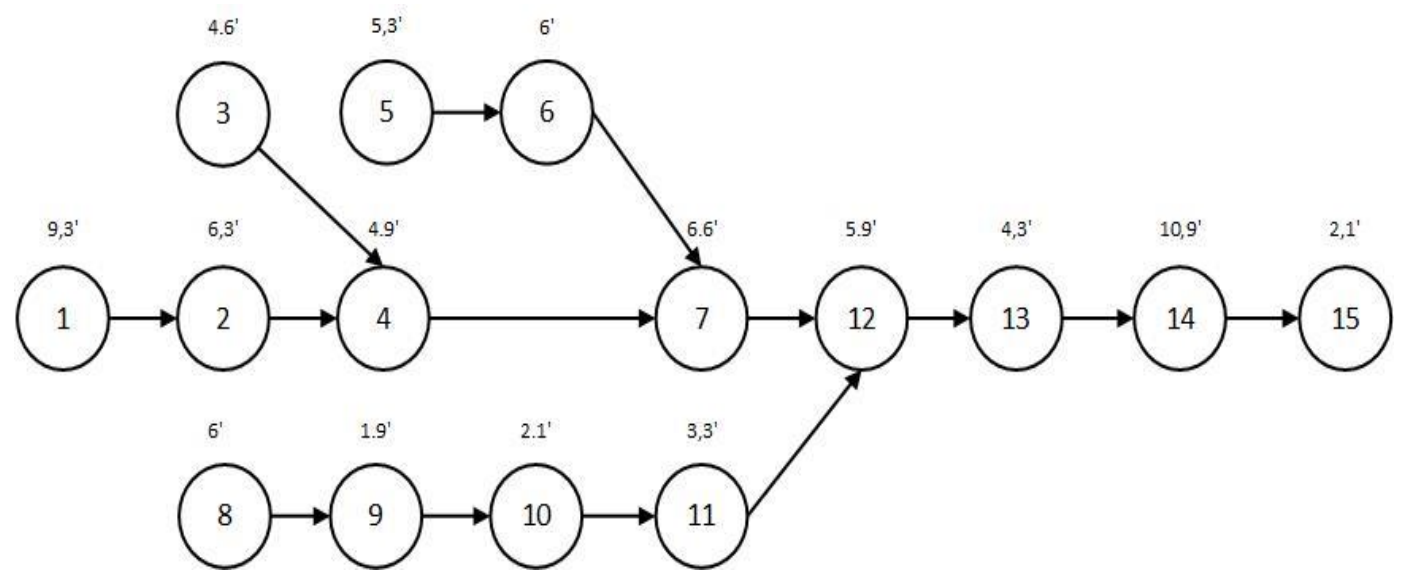

Gambar 4 Precedence Diagram Radiator Mitsubishi PS 220.

Pengolahan Data Bobot Posisi untuk Tiap Workstation

Tabel 3 Perhitungan Bobot Posisi untuk Tiap Workstation

\begin{tabular}{|c|c|c|c|c|c|c|c|c|c|c|c|c|c|c|c|c|c|}
\hline \multicolumn{10}{|c|}{ Pendahulu } & \multicolumn{10}{|c|}{ Pengikut } & \multirow{10}{*}{ } \\
\hline WS & Waktu & $\mathbf{1}$ & $\mathbf{2}$ & $\mathbf{3}$ & $\mathbf{4}$ & $\mathbf{5}$ & $\mathbf{6}$ & $\mathbf{7}$ & $\mathbf{8}$ & $\mathbf{9}$ & $\mathbf{1 0}$ & $\mathbf{1 1}$ & $\mathbf{1 2}$ & $\mathbf{1 3}$ & $\mathbf{1 4}$ & $\mathbf{1 5}$ & \\
\hline $\mathbf{1}$ & $\mathbf{9 , 3}$ & & 6,3 & 4,4 & 4,9 & 5,0 & 6,0 & 5,5 & 6,0 & 1,9 & 2,1 & 3,3 & 4,6 & 4,3 & 10,9 & 2,1 & $\mathbf{7 6 , 6}$ \\
\hline $\mathbf{2}$ & $\mathbf{6 , 3}$ & & & & 4,9 & & & 5,5 & & & & & 4,6 & 4,3 & 10,9 & 2,1 & $\mathbf{3 8 , 6}$ \\
\hline $\mathbf{3}$ & $\mathbf{4 , 4}$ & & & & 4,9 & & & 5,5 & & & & & 4,6 & 4,3 & 10,9 & 2,1 & $\mathbf{3 6 , 7}$ \\
\hline $\mathbf{4}$ & $\mathbf{4 , 9}$ & & & & & & 5,5 & & & & & 4,6 & 4,3 & 10,9 & 2,1 & $\mathbf{3 2 , 2}$ \\
\hline $\mathbf{5}$ & $\mathbf{5 , 0}$ & & & & & & & 5,5 & & & & & 4,6 & 4,3 & 10,9 & 2,1 & $\mathbf{3 2 , 4}$ \\
\hline $\mathbf{6}$ & $\mathbf{6 , 0}$ & & & & & & & 5,5 & & & & & 4,6 & 4,3 & 10,9 & 2,1 & $\mathbf{3 3 , 4}$ \\
\hline $\mathbf{7}$ & $\mathbf{5 , 5}$ & & & & & & & & & & & & 4,6 & 4,3 & 10,9 & 2,1 & $\mathbf{2 7 , 4}$ \\
\hline $\mathbf{8}$ & $\mathbf{6 , 0}$ & & & & & & & & & 1,9 & 2,1 & 3,3 & 4,6 & 4,3 & 10,9 & 2,1 & $\mathbf{3 5 , 2}$ \\
\hline $\mathbf{9}$ & $\mathbf{1 , 9}$ & & & & & & & & & & 2,1 & 3,3 & 4,6 & 4,3 & 10,9 & 2,1 & $\mathbf{2 9 , 2}$ \\
\hline $\mathbf{1 0}$ & $\mathbf{2 , 1}$ & & & & & & & & & & & & 4,6 & 4,3 & 10,9 & 2,1 & $\mathbf{2 4 , 0}$ \\
\hline $\mathbf{1 1}$ & $\mathbf{3 , 3}$ & & & & & & & & & & & & 4,6 & 4,3 & 10,9 & 2,1 & $\mathbf{2 5 , 2}$ \\
\hline $\mathbf{1 2}$ & $\mathbf{4 , 6}$ & & & & & & & & & & & & & 4,3 & 10,9 & 2,1 & $\mathbf{2 1 , 9}$ \\
\hline $\mathbf{1 3}$ & $\mathbf{4 , 3}$ & & & & & & & & & & & & & & 10,9 & 2,1 & $\mathbf{1 7 , 3}$ \\
\hline $\mathbf{1 4}$ & $\mathbf{1 0 , 9}$ & & & & & & & & & & & & & & & 2,1 & $\mathbf{1 3 , 0}$ \\
\hline $\mathbf{1 5}$ & $\mathbf{2 , 1}$ & & & & & & & & & & & & & & & & $\mathbf{2 , 1}$ \\
\hline
\end{tabular}

Berdasarkan perhitungan bobot diatas diperoleh waktu proses workstation terbesar adalah pada workstation 14 yaitu 10,9 menit. 


\section{Pengurutan Prioritas Workstation Berdasarkan Bobot Posisi}

Berdasarkan hasil perhitungan bobot diatas diperoleh urutan prioritas workstation, dimana bobot yang terbesar merpakan prioritas pertama sedangkan bobot yang terkecil merpakan prioritas terakhir. Pengurutan prioritas workstation dapat dilihat pada tabel 4 dibawah ini.

Tabel 4 Pengurutan Prioritas Workstation Berdasarkan Bobot Posisi

\begin{tabular}{|c|c|c|}
\hline Prioritas & Operasi & Bobot \\
\hline $\mathbf{1}$ & 1 & 76,6 \\
\hline $\mathbf{2}$ & 2 & 38,6 \\
\hline $\mathbf{3}$ & 3 & 36,7 \\
\hline $\mathbf{4}$ & 8 & 35,2 \\
\hline $\mathbf{5}$ & 6 & 33,4 \\
\hline $\mathbf{6}$ & 5 & 32,4 \\
\hline $\mathbf{7}$ & 4 & 32,2 \\
\hline $\mathbf{8}$ & 9 & 29,2 \\
\hline $\mathbf{9}$ & 7 & 27,4 \\
\hline $\mathbf{1 0}$ & 11 & 25,2 \\
\hline $\mathbf{1 1}$ & 10 & 24,0 \\
\hline $\mathbf{1 2}$ & 12 & 21,9 \\
\hline $\mathbf{1 3}$ & 13 & 17,3 \\
\hline $\mathbf{1 4}$ & 14 & 13,0 \\
\hline $\mathbf{1 5}$ & 15 & 2,1 \\
\hline
\end{tabular}

\section{Penentuan Jumlah Workstation Baru}

Berdasarkan nilai bobot terbesar, jumlah workstation yang ideal untuk pembuatan radiator mitsubishi PS220 sebanyak 8 workstation. Dimana untuk mengetahui jumlah workstation yang ideal dengan menggunakan formulasi seperti dibawah ini.

$K=\frac{\sum t i}{C} x 100 \%$

$K=\frac{76,6}{10,9} x 100 \%=7,01=8$ workstation

Pembebanan Workstation Lama ke Workstation Baru

Tabel 5 Pembebanan Workstation Lama ke Workstation Baru

\begin{tabular}{|c|c|c|}
\hline $\begin{array}{c}\text { Stasiun Kerja } \\
\text { Baru }\end{array}$ & $\begin{array}{c}\text { Stasiun Kerja } \\
\text { Lama }\end{array}$ & Waktu Kumulatif \\
\hline $\mathbf{1}$ & 1 & 9,3 \\
\hline \multirow{2}{*}{$\mathbf{2}$} & 2 & \multirow{2}{*}{10,7} \\
\cline { 2 - 2 } & 3 & \multirow{2}{*}{1} \\
\hline \multirow{2}{*}{3} & 8 & \multirow{2}{*}{10,0} \\
\cline { 2 - 2 } & 9 & \multicolumn{2}{|c|}{} \\
\cline { 2 - 2 } & 10 & \\
\hline
\end{tabular}


. Tabel 5 Pembebanan Workstation Lama ke Workstation Baru (lanjutan)

\begin{tabular}{|c|c|c|}
\hline $\begin{array}{c}\text { Stasiun Kerja } \\
\text { Baru }\end{array}$ & $\begin{array}{c}\text { Stasiun Kerja } \\
\text { Lama }\end{array}$ & Waktu Kumulatif \\
\hline \multirow{2}{*}{4} & 6 & \multirow{2}{*}{9,3} \\
\hline & 11 & \\
\hline \multirow{2}{*}{5} & 4 & \multirow{2}{*}{9,9} \\
\hline & 5 & \\
\hline \multirow{2}{*}{6} & 7 & \multirow{2}{*}{10,0} \\
\hline & 12 & \\
\hline \multirow{2}{*}{7} & 13 & \multirow{2}{*}{6,4} \\
\hline & 15 & \\
\hline 8 & 14 & 10,9 \\
\hline \multicolumn{2}{|c|}{$\sum$} & 76,6 \\
\hline
\end{tabular}

Tabel 5 diatas merupakan hasil penggabungan beberapa workstation, dimana ketika ditotalkan waktu baku workstation yang dilakukan penggabungan akan mendakati atau bahkan akan sama dengan waktu baku yang terbesar pada workstation 14. Prinsipnya ketika melakukan penggabungan workstation, waktu bakunya tidak boleh melebihi waktu baku yang terbesar.

Adapun perhitungan matematis sebagai berikut:

1. Workstation 1 Baru

9,3 menit

2. Workstation 2 Baru

Ws $2+$ Ws 3

$6,3+4,4=10,7$ menit

3. Workstation 3 Baru

Ws $8+$ Ws $9+$ Ws 10

$6,0+1,9+2,1=10,0$ menit

4. Workstation 4 Baru

Ws $6+$ Ws 11

$6,0+4,6=10,6$ menit

5. Workstation 5 Baru

Ws $4+$ Ws 5

$4,9+5,0=9,9$ menit

6. Workstation 6 Baru

Ws $7+$ Ws 12

$5,5+4,6=10,0$ menit

7. Workstation 7 Baru

Ws $13+$ Ws 15

$4,3+2,1=6,4$ menit

8. Workstation 8 Baru

10,9 menit 


\section{Pengolahan Data Waktu Menganggur (Idle Time)}

Tabel 6 Pengolahan Data Waktu Menganggur (Idle Time) Sebelum Line Balancing

\begin{tabular}{|c|c|c|}
\hline $\begin{array}{c}\text { Stasiun } \\
\text { Kerja }\end{array}$ & $\begin{array}{c}\text { Waktu } \\
\text { Kumulatif }\end{array}$ & Idle \\
\hline $\mathbf{1}$ & 9,3 & 1,6 \\
\hline $\mathbf{2}$ & 6,3 & 4,6 \\
\hline $\mathbf{3}$ & 4,4 & 6,5 \\
\hline $\mathbf{4}$ & 4,9 & 6,1 \\
\hline $\mathbf{5}$ & 5,0 & 5,9 \\
\hline $\mathbf{6}$ & 6,0 & 5,0 \\
\hline $\mathbf{7}$ & 5,5 & 5,5 \\
\hline $\mathbf{8}$ & 6,0 & 5,0 \\
\hline $\mathbf{9}$ & 1,9 & 9,0 \\
\hline $\mathbf{1 0}$ & 2,1 & 8,8 \\
\hline $\mathbf{1 1}$ & 3,3 & 7,6 \\
\hline $\mathbf{1 2}$ & 4,6 & 6,3 \\
\hline $\mathbf{1 3}$ & 4,3 & 6,6 \\
\hline $\mathbf{1 4}$ & 10,9 & 0,0 \\
\hline $\mathbf{1 5}$ & 2,1 & 8,8 \\
\hline$\sum$ & 76,6 & 87,3 \\
\hline & & \\
\hline
\end{tabular}

Adapun perhitungan matematis sebagai berikut:

$$
\text { Idle Time }=W s-W i
$$

1. Workstation 1

Idle Time $=10,9-9,3=1,6$ menit

2. Workstation 2

Idle Time $=10,9-6,3=4,6$ menit

3. Workstation 3

Idle Time $=10,9-4,4=6,5$ menit

4. Workstation 4

Idle Time $=10,9-4,9=6,1$ menit

5. Workstation 5

Idle Time $=10,9-5,0=5,9$ menit

6. Workstation 6

Idle Time $=10,9-6,0=5,0$ menit

7. Workstation 7

Idle Time $=10,9-5,5=5,5$ menit

8. Workstation 8

Idle Time $=10,9-6,0=5,0$ menit

9. Workstation 9

Idle Time $=10,9-1,9=9,0$ menit 
10. Workstation 10

Idle Time $=10,9-2,1=8,8$ menit

11. Workstation 11

Idle Time $=10,9-3,3=7,6$ menit

12. Workstation 12

Idle Time $=10,9-4,6=6,3$ menit

13. Workstation 13

Idle Time $=10,9-4,3=66$ menit

14. Workstation 14

Idle Time $=10,9-10,9=0$ menit

15. Workstation 15

Idle Time $=10,9-2,1=8,8$ menit.

Tabel 6 Pengolahan Data Waktu Menganggur (Idle Time) Setelah Line Balancing

\begin{tabular}{|c|c|c|c|}
\hline $\begin{array}{c}\text { Stasiun } \\
\text { Kerja } \\
\text { Baru }\end{array}$ & $\begin{array}{c}\text { Stasiun } \\
\text { Kerja } \\
\text { Lama }\end{array}$ & $\begin{array}{c}\text { Waktu } \\
\text { Kumulatif }\end{array}$ & Idle \\
\hline 1 & 1 & 9,3 & 1,6 \\
\hline \multirow{2}{*}{2} & 2 & \multirow{2}{*}{10,7} & \multirow{2}{*}{0,2} \\
\hline & 3 & & \\
\hline \multirow{3}{*}{3} & 8 & \multirow{3}{*}{10,0} & \multirow{3}{*}{0,9} \\
\hline & 9 & & \\
\hline & 10 & & \\
\hline \multirow{2}{*}{4} & 6 & \multirow{2}{*}{9,3} & \multirow{2}{*}{1,6} \\
\hline & 11 & & \\
\hline \multirow{2}{*}{5} & 4 & \multirow{2}{*}{9,9} & \multirow{2}{*}{1,0} \\
\hline & 5 & & \\
\hline \multirow{2}{*}{6} & 7 & \multirow{2}{*}{10,0} & \multirow{2}{*}{0,9} \\
\hline & 12 & & \\
\hline \multirow{2}{*}{7} & 13 & \multirow{2}{*}{6,4} & \multirow{2}{*}{4,5} \\
\hline & 15 & & \\
\hline 8 & 14 & 10,9 & 0,0 \\
\hline \multicolumn{2}{|c|}{$\sum$} & 76,6 & 10,8 \\
\hline
\end{tabular}

Adapun perhitungan matematis sebagai berikut:

Idle Time $=W s-W i$

1. Workstation 1

Idle Time $=10,9-9,3=1,6$ menit

2. Workstation 2

Idle Time $=10,9-10,7=0,2$ menit

3. Workstation 3

Idle Time $=10,9-10,0=0,9$ menit 
4. Workstation 4

Idle Time $=10,9-9,3=1,6$ menit

5. Workstation 5

Idle Time $=10,9-9,9=1$ menit

6. Workstation 6

Idle Time $=10,9-10=0,9$ menit

7. Workstation 7

Idle Time $=10,9-6,4=4,5$ menit

8. Workstation 8

Idle Time $=10,9-10,9=0$ menit.

Berdasarkan dari perhitungan waktu menganggur diatas dapat disimpulkan bahwa waktu menganggur setelah dilakukan line balancing mengalami penurunan.

Pengolahan Data Keseimbangan Waktu Senggang (Balance Delay)

Tabel 7 Pengolahan Data Keseimbangan Waktu Senggang (Balance Delay)

\begin{tabular}{|c|c|c|}
\hline $\begin{array}{c}\text { Faktor } \\
\text { Pembanding }\end{array}$ & $\begin{array}{c}\text { Sebelum Line } \\
\text { Balancing }\end{array}$ & $\begin{array}{c}\text { Setelah Line } \\
\text { Balancing }\end{array}$ \\
\hline Balance Delay & 53,26 & 12,36 \\
\hline
\end{tabular}

Adapun formulasi matematis sebagai berikut:

$B D=\frac{n \cdot C-\sum t i}{n \cdot t i} x 100 \%$

1. Sebelum Line Balancing

$$
B D=\frac{15 \cdot 10,9-76,6}{15.10,9} \times 100 \%=53,26 \%
$$

2. Setelah Line Balancing

$$
B D=\frac{8.10,9-76,6}{8.10,9} \times 100 \%=12,36 \% .
$$

Berdasarkan hasil perhitungan balance delay dapat diketahui bahwa setelah dilakukan line balancing waktu senggang menurun menjadi 12,36\% dibandingkan sebelumnya sebsar 53,26\%.

\section{Pengolahan Data Efisiensi Lintasan Produksi (Line Efficiency)}

Tabel 8 Pengolahan Data Data Efisiensi Lintasan Produksi (Line Efficiency)

\begin{tabular}{|c|c|c|}
\hline $\begin{array}{c}\text { Faktor } \\
\text { Pembanding }\end{array}$ & $\begin{array}{c}\text { Sebelum Line } \\
\text { Balancing }\end{array}$ & $\begin{array}{c}\text { Setelah Line } \\
\text { Balancing }\end{array}$ \\
\hline Line Efficiency & 46,74 & 87,64 \\
\hline
\end{tabular}

Adapun perhitungan matematis sebagai berikut:

$E f f=\frac{S T i}{n . C} \times 100 \%$

1. Sebelum Line Balancing

$$
E f f=\frac{10,9}{15.10,9} \times 100 \%=46,74 \%
$$


2. Setelah Line Balancing

$$
E f f=\frac{10,9}{8.10,9} \times 100 \%=87,64 \%
$$

Berdasarkan hasil perhitungan line eficiency dapat diketahui bahwa setelah dilakukan line balancing waktu senggang meningkat menjadi $87,64 \%$ dibandingkan sebelumnya sebsar 46,74\%.

\section{KESIMPULAN DAN SARAN}

Berdasarkan hasil penelitian dan pembahasan, maka didapatkan kesimpulan sebagai berikut:

1. Waktu baku tiap workstation pada proses pembuatan radiator Mitsubishi PS 220 yaitu workstation 1 rakit core 9,3 menit, workstation 2 oven 6,3 menit, workstation 3 press end plate 4,4 menit, workstation 4 pasang end plate 4,9 menit, workstation 5 press tank 5,0 menit, workstation 6 tank assy 6,0 menit, workstation 7 pasang tank 5,5 menit, workstation 8 punch 6,0 menit, workstation 9 shering 1,9 menit, workstation 10 bending 2,1 menit, workstation 11 spot 3,3 menit, workstation 12 pasang side plate 4,9 menit, workstation 13 leaktest 4,3 menit, workstation 14 painting 10,9 menit, dan workstation 15 packaging 2,1 menit.

2. Dari gambar 1 diagram perbandingan waktu baku terlihat bahwa yang menjadi penyebab ketidakseimbangam lintasan adalah workstation 1 rakit core 9,3 menit, workstation 14 painting 10,9 menit.

3. Lintasan yang efisien setelah line balancing sebesar $87,64 \%$ dengan penggabungan workstation 2 dengan workstation 3, workstation 8 dengan workstation 9 dan 10, workstation 6 dengan workstation 11, workstation 4 dengan workstation 5, workstation 7 dengan workstation 12, workstation 13 dengan workstation 15 yang menghasilkan 8 workstations.

Saran yang dapat diberikan dari peneliti adalah sebagai berikut :

1. Agar sistem informasi ini dapat dijalankan dengan berkelanjuatan dan maksimal, perusahaan harus melakukan evaluasi secara berkesinambungan.

2. Metode ini dapat digunakan pada pembuatan produk radiator model lainnya

\section{DAFTAR PUSTAKA}

Azwir, Hery Hamdi. dan Pratomo, Harry Wahyu. (2017). Implementasi Line Balancing untuk Peningkatan Efisiensi di Line Welding Studi Kasus: PT X. Jurnal Rekayasa Sistem Industri, Vol 6, No.1, April 2017.

Ekoanindiyo, Firman Ardiansyah. dan Helmy, Latif. (2017). Meningkatkan Efisiensi Lintasan Kerja Menggunakan Metode Rpw Dan Killbridge-Western. Dinamika Teknik, Vol. X, No. 1, Jan 2017, Hal $16-26$

Ghozali, M. Wildan. dan Hermansyah, M. Pengukuran Waktu Baku Proses Finishing Line Volpak Produksi Lannate Sp 25 Gram Philipina Guna Meningkatkan Produktivitas (Pt. Dupont Agricultural Products Indonesia). Journal Knowledge Industrial Engineering (JKIE), Vol. 03/No. 03/2016, Hal 31-39.

Gozali, Lina, dkk. (2012). Perbaikan Lini Finishing Drive Chain Ahm Oem Pada Pt Federal Superior Chain Manufacturing Dengan Metode Keseimbangan Lini Dan Methods Time Measurement. Jurnal Teknik dan Ilmu Komputer, Vol. 01 No. 02, Apr - Jun 2012.

Karo-Karo, Gidion. dan Hendra, Seri. (2015). Usulan Peningkatan Efisiensi Stasiun Kerja Pada Lini Perakitan Current Coil (Studi Kasus: Pt. Padma Soode Indonesia). Journal of Industrial Engineering \& Management Systems, Vol. 8, No 2, August 2015.

Kusuma, Hendra. (2009). Manajemen Produksi Perancangan \& Pengendalian Produksi. Yogyakarta: CV Andi Offset

Santoso, Gempur. (2013). Ergonomi Terapan. Jakarta: Prestasi Pustaka Publisher. 
Setyawan, David, dkk. (2012). Perbaikan Sistem Produksi Dengan Metode Line Balancing Pada Perusahaan Pembuat Mesin Pertanian PT Agrindo Di Gresik. Jurnal Ilmiah Mahasiswa Universitas Surabaya, Vol.1, No.1.

Sinulingga, Sukaria. (2013). Pengantar Teknik Industri. Yogyakarta: Graha Ilmu.

Sukania , I Wayan. Dan Gunawan, Teddy. (2014). Analisa Waktu Baku Elemen Kerja pada Pekerjaan Penempelan Cutting Stiker di CV Cahaya Thesani. Jurnal Energi dan Manufaktur Vol.7, No.2, Oktober 2014: 119-224.

Sutalaksana, Iftikar Z, dkk. (2006). Teknik Perancangan Sistem Kerja. Bandung: ITB.

Syukron, Amin. dan Kholil, Muhammad. (2014). Pengantar Teknik Industri. Yogyakarta: Graha Ilmu.

Wahyuniardi, Rizki. dkk. (2012). Perbaikan Keseimbangan Lintasan Perakitan Dengan Algoritma Genetika (Studi Kasus Di Cv. Jaya Pratama Bandung). Seminar Nasional Mesin Dan Industri (Snmi7) 2012.

Wibowo, Arif. (2008). Penentuan Standar Waktu Kerja Dan Harga Jual Produk Menggunakan Model Sistem Informasi Manajemen. Skripsi, Jurusan Teknik Industri Fakultas Teknik Universitas Muhammadiyah Surakarta.

Wignjosoebroto, Sritomo. (2017). Ergonomi, Studi Gerak dan Waktu. Surabaya: Guna Widya.

Wignjosoebroto, Sritomo. (2006). Pengantar Teknik dan Manajemen Industri. Surabaya: Guna Widya. 
